\title{
Factors influencing GPs' perception of specialised palliative homecare (SPHC) importance - results of a cross-sectional study
}

K. Stichling ${ }^{1}$, M. Krause ${ }^{1}$, B. Ditscheid ${ }^{1}$, M. Hach², M. Jansky ${ }^{3}$, M. Kaufmann¹, T. Lehmann ${ }^{4}$, W. Meißner ${ }^{5}$, F. Nauck ${ }^{3}$, W. Schneider ${ }^{6}$, S. Schulz ${ }^{1}$, H. C. Vollmar ${ }^{1,7}$, U. Wedding ${ }^{5}$, J. Bleidorn ${ }^{1}$, A. Freytag ${ }^{1 *}$ (D) and the SAVOIR Study Group

\begin{abstract}
Background: General Practitioners (GPs) are the main providers of primary palliative care (PPC). At the same time they are the main initiators of specialised palliative homecare (SPHC). In Germany, little is known about factors which influence GPs in their involvement of SPHC. Aim of our study is to identify factors that drive GPs to give value to and involve SPHC.
\end{abstract}

Methods: A cross-sectional survey was performed. In 2018, questionnaires were mailed to 6000 randomly selected GPs from eight German federal states, focusing on the extent of GPs' palliative care activities and their involvement of SPHC.

Results: With a response rate of $19.4 \%$ and exclusion of GPs working in SPHC-teams, $n=1026$ questionnaires were appropriate for analysis. GPs valued SPHC support as the most "important/very important" for both "technical/ invasive treatment measures" (95\%) and availability outside practice opening hours (92\%).

The most relevant factor influencing perceived SPHC-importance was GPs' self-reported extent of engagement in palliative care $(\beta=-0.283$; Cl 95\% = -0.384; -0.182$)$, followed by the perceived quality of utilised SPHC $(\beta=0.119 ; \mathrm{Cl}$ $95 \%=0.048 ; 0.190)$, involvement in treatment of palliative patients after SPHC initiation $(\beta=0.088 ; \mathrm{Cl} 95 \%=0.042$; $0.134)$, and conviction that palliative care should be a central part of GPs' work ( $\beta=-0.062 ; \mathrm{Cl} 95 \%=-0.116$; -0.008). Perceived SPHC-importance is also associated with SPHC-referrals $(\beta=0.138 ; p<0.001)$. The lower the engagement of GPs in palliative care, the more they involve SPHC and vice versa.

Conclusions: GPS with low reported activity in palliative care are more likely to initialise SPHC for palliative care activities they do not deliver themselves for various reasons, which might mean that the involvement of SPHC is substitutive instead of complementary to primary palliative care. This finding and its interpretation should be given more attention in the future policy framework for (specialised) palliative homecare.

Trial registration: German Clinical Trials Register DRKS00014726, 14.05.2018.

Keywords: General practice, Primary palliative care, Specialised palliative homecare, Home care service, Surveys and questionnaires, Cross-sectional survey, Policy implications

\footnotetext{
* Correspondence: antje.freytag@med.uni-jena.de

'Institute of General Practice and Family Medicine, Jena University Hospital, Jena, Germany

Full list of author information is available at the end of the article
}

(c) The Author(s). 2020 Open Access This article is licensed under a Creative Commons Attribution 4.0 International License, which permits use, sharing, adaptation, distribution and reproduction in any medium or format, as long as you give appropriate credit to the original author(s) and the source, provide a link to the Creative Commons licence, and indicate if changes were made. The images or other third party material in this article are included in the article's Creative Commons licence, unless indicated otherwise in a credit line to the material. If material is not included in the article's Creative Commons licence and your intended use is not permitted by statutory regulation or exceeds the permitted use, you will need to obtain permission directly from the copyright holder. To view a copy of this licence, visit http://creativecommons.org/licenses/by/4.0/ The Creative Commons Public Domain Dedication waiver (http://creativecommons.org/publicdomain/zero/1.0/) applies to the data made available in this article, unless otherwise stated in a credit line to the data. 


\section{Background}

In Germany, similar to other high-income countries, specialised palliative homecare (SPHC) has evolved during recent decades to deliver homecare for patients with particularly complex palliative needs. As SPHC demands more resources than primary palliative care (PPC, Table 1), according to the Social Health Insurance legislation [3] ( $\$ 1$ Abs. 6), SPHC can be referred to if there is medical need for specialist palliative care and PPC alone is not sufficient. Thus, SPHC provides complementary care to enable homecare until the end of life even for patients in complex situations (Table 1).

Since the introduction of SPHC in 2007, the number of SPHC referrals has continued to rise [4], though with strong regional variations [2].

While GPs are the main providers who take responsibility for outpatient palliative care activities (most of them within PPC but some of them as additionally qualified physicians in SPHC teams), they are at the same time the main initiators and refer to SPHC [5]. This crucial role has not yet been explored sufficiently [6]. We know some of the factors driving GPs' involvement in palliative care $[7,8]$ as well as hindering and promoting factors for cooperation between GPs and specialist palliative care teams [9]. There are findings, that GPs lack confidence and skill in identifying and caring for complex patients and time for professional development in palliative care [10]. Working in smaller GP practices, having limited current involvement in palliative care provision, and having less experience or education in palliative care were identified as factors facilitating British GPs in handing over to specialists by a qualitative study [11].

However, we lack reliable evidence about the factors that drive GPs to involve SPHC, which could provide insight into the interrelation of PPC and SPHC. Such evidence is required for further developing the policy framework for both SPHC and PPC, in order to promote access, effectiveness and efficiency for patients in need of palliative care.
To explore the factors that determine the valuing of and involvement in SPHC on behalf of GPs, we conducted a written survey of 6000 GPs in eight federal states in Germany.

This study is part of the collaborative research project SAVOIR (evaluation of specialised palliative homecare (SPHC) in Germany: outcomes, interactions, regional differences) [12].

\section{Methods}

\section{Hypothesis/Theory}

We hypothesised that there are more factors implicated than medical indication of patients' special need when German GPs involve SPHC. From this survey, we expected insight into a large set of physician-related, practice-related, environmental factors, and in particular, the GPs' own provision of general palliative care activities as potential factors driving GPs to involve SPHC.

\section{Study design}

We performed a cross-sectional study among GPs in eight German federal states. The data were generated from a postal questionnaire.

\section{Survey setting and sample}

In Germany, the regular delivery of primary health care is organised by 17 Associations of Statutory Health Insurance Physicians ("Kassenärztliche Vereinigung") corresponding to the federal states.

From the 17 Associations, eight were selected for their greatest heterogeneity regarding structures and policy framework in SPHC (different forms delivery contracts, ownership, team structure, remuneration systems), as well as the number of inhabitants and size. A randomly selected sample of 6000 GPs within these federal states ( $n=750$ each) were invited to participate.

\section{Instrument}

The development of the six-page questionnaire is explained in Additional file 1.

Table 1 Two kinds of palliative homecare in Germany

PPC

$\gg$ Palliative homecare is mostly delivered as primary palliative care (PPC) [1]).

$\gg$ PPC provided by General Practitioners (GPs) is often supported by nursing care services, ambulatory hospice services, etc.

$\gg$ About $90 \%$ of patients at end of life can be sufficiently cared for with PPC, according to estimations of the German Association of Palliative Medicine [2].

\section{SPHC}

$>$ Specialised palliative homecare (SPHC) for patients with severe, advanced, life-limiting illnesses and complex symptoms is funded by the Social Health Insurance.

>is provided by multi-professional teams (physicians, nurses, other professionals), delivering specialised palliative care at patients' homes/ nursing homes etc. [3].

$>$ comprises care which in kind, severity and complexity can only be delivered by physicians with extra palliative qualifications, as well as 24-h availability.

> requires a referral from GPs, primary care specialists or upon discharge from hospital.

$>$ main indications are complex, pronounced symptoms such as neurological, psychiatric or psychological, respiratory or cardiac symptoms, ulcerating wounds or tumours. 
The questionnaire (Additional file 2) comprised of more than 100 items focusing on physician-related characteristics, such as experience with and qualifications in palliative care, self-assessed competence and role in palliative care, workload and practice-related factors, as well as SPHC referral practice, and availability/quality of care of the surrounding palliative care infrastructure. In particular, GPs were asked how often they perform activities for their palliative patients out of the following five categories: assessment and planning of care; symptom management; interventions; coordination of care; and availability. In addition, GPs assessed their need for support from palliative specialists for each activity.

\section{Data collection and consent of participants}

The survey was undertaken from March to May 2018. All questionnaires were accompanied by a personalised letter and a self-addressed stamped envelope. Reminders were sent to all 6000 GPs after four and six weeks, respectively. Informed consent was implied if the completed questionnaire was sent back. After data collection, questionnaires were transcribed electronically into a SPSS Statistics database. Missing values were defined in advance. To ensure the quality of data, a $100 \%$ full check of the questionnaires was conducted, revealing no substantial mismatch between the imported data and the original questionnaires.

\section{Data analysis}

Statistical analyses were performed using SPSS Version 25 for Windows.

For valued SPHC support, an additional variable, "SPHC importance index", was calculated from the average of all sub-questions about palliative activities. With this index, the intensity to which respondents valued SPHC support was qualified on a continuous scale with a minimum score of 1 ("not required") and a maximum score of 3 ("very important"). For the aggregation of GPs' extent that they are engaged in palliative care delivery, the "GPs palliative care activity index" was calculated from the average of all sub-questions about palliative activities delivered by GPs from the assessed range from $1=$ never to $4=$ always.

To analyse which factors were associated with GPs' perception of the importance of SPHC, we performed univariate and multiple linear regression using all independent variables with the new variable SPHC importance index as the dependent variable. All characteristics were simultaneously entered into the model to calculate the independent effects. The results were considered statistically significant if $\mathrm{p} \leq 0.05$.

\section{Results}

Reporting refers to the internationally accepted standards of good practice in reporting of survey research (i.e. STROBE) [13, 14].

\section{Characteristics of respondents}

The response rate was 19.4\% $(n=1166) .1144(19.1 \%)$ questionnaires were eligible. GPs working as a part of a SPHC team $(n=118 ; 10.3 \%)$ were excluded from further analysis due to possible conflict of interest. This left a number of $n=1026$ questionnaires to be analysed.

Table 2 shows the characteristics of the respondents. About half of the GPs were female (50.8\%). The average age was 54.1 years, $49.8 \%$ worked in a single-handed practice, $45.6 \%$ in a group practice and a smaller number in a medical care centre (4.6\%). GPs cared, on average, for 18.4 palliative patients $(S D=26.8 ; \quad$ Median $=10$, $\mathrm{IQR}=14$ ) over the past year. The vast majority of the respondents $(83.7 \%)$ had already referred to SPHC.

For non-responder analysis, we performed a statistical comparison between the characteristics of participating GPs and average German GPs [15]. Respondents were more likely to be female ( $50.8 \%$ vs $46.3 \%$ ) and have additional qualifications in palliative care $(9.7 \%$ vs $3.5 \%)$. Older GPs (> 65 years) were less likely to participate in our survey (9.9\% vs $16.3 \%)$.

\section{GPs' evaluation of SPHC importance}

In total, the SPHC importance index averaged 2.25 $(\mathrm{SD}=0.51, n=956, \min =0, \max =3)$ on a continuous scale with 1 "not required", 2 "important" and 3 "very important" reflecting an overall high rating of the importance of SPHC services by GPs. However, results for single activities for which GPs consider the support of a specialised palliative care team beneficial (Additional file 3) reveal substantial variations: "Technical and invasive treatment measures" was the activity where support was most frequently deemed beneficial by GPs (73\% "very important" and 22\% "important"). SPHC support in "treatment in the final phase" was also valued as "very important" (59\%) or "important" (32\%) . For providing 24-h availability to the patient and relatives in the form of home visits outside practice opening hours, support by SPHC was rated "very important" (66\%) or "important" (25\%). SPHC support through telephone advice outside practice opening hours was similarly rated as "very important" (65\%) or "important" (25\%).

Approximately $44 \%$ of the GPs declared no need for support in terms of "advice/assistance in advance directive and power of attorney for personal care" and "treatment of chronic diseases" (41\%) which were the highest scores for "not required". 
Table 2 Characteristics of respondents and practice of SPHC referrals ${ }^{a}$

\begin{tabular}{|c|c|c|c|c|}
\hline Characteristics & Value & & & \\
\hline Respondents - $\mathrm{n}$ & 1026 & & & \\
\hline Age - years Mean \pm SD & $54.1 \pm 9.4$ & & & \\
\hline \multicolumn{5}{|l|}{ Gender - n (\%) } \\
\hline Male & $502(49.0)$ & & & \\
\hline Female & $520(50.8)$ & & & \\
\hline Work experience in the outpatient sector - years Mean \pm SD & $20.2 \pm 11.2$ & & & \\
\hline Working hours/week - Mean \pm SD & $46.9 \pm 12.4$ & & & \\
\hline \multicolumn{5}{|l|}{ Practice type - n (\%) } \\
\hline Single-handed & $510(49.8)$ & & & \\
\hline Group practice & $467(45.6)$ & & & \\
\hline Medical care centre & $47(4.6)$ & & & \\
\hline \multicolumn{5}{|l|}{ Employed - n (\%) } \\
\hline Yes & $123(12.0)$ & & & \\
\hline No & $887(86.6)$ & & & \\
\hline \multicolumn{5}{|l|}{ Location of practice - $\mathrm{n}(\%)$} \\
\hline Rural ( $\leq 5,000$ inhabitants) & $264(25.8)$ & & & \\
\hline Small town (> 5,000-20,000 inhabitants) & $290(28.3)$ & & & \\
\hline Medium-sized town (> 20,000-100,000 inhabitants) & $198(19.3)$ & & & \\
\hline Big city (> 100,000 inhabitants) & $264(25.8)$ & & & \\
\hline Number of patients/quarter - Mean \pm SD & $\begin{array}{l}1130.3 \pm \\
373.3\end{array}$ & & & \\
\hline Number of palliative patients/year - Mean \pm SD & $18.4 \pm 26.8$ & & & \\
\hline Number of home visits/week - Mean \pm SD & $15.3 \pm 20.6$ & & & \\
\hline Number of home visits/quarter within palliative patients - Mean \pm SD & $15.1 \pm 25.5$ & & & \\
\hline \multicolumn{5}{|l|}{ GPs' attitude towards palliative care } \\
\hline & bad & $\ldots$ & $\ldots$ & good \\
\hline \multirow[t]{2}{*}{ Please assess your overall palliative competence/expertise! - n (\%) } & $20(2.0)$ & $90(8.8)$ & $533(52.1)$ & $350(34.2)$ \\
\hline & not true & $\begin{array}{l}\text { rather not } \\
\text { true }\end{array}$ & $\begin{array}{l}\text { rather } \\
\text { true }\end{array}$ & $\begin{array}{l}\text { completly } \\
\text { true }\end{array}$ \\
\hline Care of severe sick and dying patients should be a central part of GPs work. - n (\%) & $34(3.3)$ & $106(10.4)$ & $219(21.4)$ & $657(64.2)$ \\
\hline
\end{tabular}

\section{SPHC referral practice}

Have you ever referred SPHC (within your work as a GP)?

$$
\begin{aligned}
& \text { Yes - } \mathrm{n}(\%) \\
& \text { No - } \mathrm{n}(\%) \\
& \text { Number of GPS' SPHC referrals (follow-up referrals included) - Mean } \pm \text { SD } \\
& \text { Number of SPHC referrals by other health care professionals - Mean } \pm \text { SD }
\end{aligned}
$$

Do you regularly stay involved in palliative patients' treatment after SPHC initiation? - n (\%)

How often is one of your SPHC referrals denied (by MDK)? - n (\%)

${ }^{a}$ Not all respondents answered every question. Percent does not add up to 100 due to rounding and non-responses

${ }^{\mathrm{b}}$ Medical advisary service of Social Health Insurance (MDK: Medizinischer Dienst der Krankenkassen)

Factors influencing GPs' perception of the importance of SPHC

In univariate analyses (Table 3), variables which contributed to a higher SPHC importance index were (descending order according to regression coefficient): perceived quality of utilised SPHC services, gender (female), and quality of surrounding palliative infrastructure. Additionally, if GPs felt regularly involved in the 
Table 3 GPs' evaluation of SPHC importance (index), univariate analyses

\begin{tabular}{|c|c|c|c|c|c|}
\hline Variable & $\begin{array}{l}\text { Regression } \\
\text { Coefficient } \beta\end{array}$ & Significance & $\begin{array}{l}95 \% \text { Confidence } \\
\text { Interval }\end{array}$ & Standard Error & $\mathrm{n}$ \\
\hline Age & -.002 & .238 & $-.006 ; .001$ & .002 & 954 \\
\hline Gender (Reference: male) & .158 & $<.001$ & $.093 ; .223$ & .033 & 955 \\
\hline Work experience (years) & -.003 & .023 & $\begin{array}{l}-.006 \\
-4.8^{*} 10 \wedge(-4)\end{array}$ & .002 & 948 \\
\hline Working hours/week & -.005 & $<.001$ & $-.008 ;-.002$ & .001 & 944 \\
\hline Practice Type (Reference: medical care centre) & & & & & 956 \\
\hline Single-handed & -.123 & .128 & $-.281 ; .035$ & .081 & \\
\hline Group practice & -.123 & .128 & $-.282 ; .035$ & .081 & \\
\hline Employed (reference: yes) & -.064 & .218 & $-.165 ; .038$ & .052 & 943 \\
\hline Location of practice (reference: big city) & & & & & 949 \\
\hline Rural & -.084 & .070 & $-.176 ; .007$ & .047 & \\
\hline Small town & -.057 & .212 & $-.147 ; .033$ & .046 & \\
\hline Medium-sized town & -.078 & .124 & $-.177 ; .021$ & .050 & \\
\hline
\end{tabular}

Affiliation to Federal State (association of Statuatory Health Insurance Physicians, reference: Westphalia-Lippe)

\begin{tabular}{|c|c|c|c|c|c|}
\hline Bavaria & .039 & .561 & $-.093 ; .171$ & .067 & \\
\hline Berlin & .227 & .003 & $.076 ; .378$ & .077 & \\
\hline Hesse & .144 & .040 & $.006 ; .282$ & .070 & \\
\hline Lower Saxony & .108 & .133 & $-.033 ; .248$ & .072 & \\
\hline Saxony-Anhalt & .068 & .313 & $-.064 ; .200$ & .067 & \\
\hline Schleswig-Holstein & .083 & .235 & $-.054 ; .220$ & .070 & \\
\hline Thuringia & .122 & .056 & $-.003 ; .247$ & .064 & \\
\hline Number of patients/quarter & $-9.08 * 10 \wedge(-5)$ & .048 & $-1.81^{*} 10 \wedge(-4)$ & $-7.68^{*} 10 \wedge(-7)$ & 910 \\
\hline Number of palliative patients/year & -.001 & .081 & $\begin{array}{l}-.002 \\
1.40^{*} 10 \wedge(-4)\end{array}$ & .001 & 940 \\
\hline Number of home visits/week & -.001 & .096 & $\begin{array}{l}-.003 ; \\
2.42^{*} 10 \wedge(-4)\end{array}$ & .001 & 954 \\
\hline Number of home visits/quarter within palliative patients & $-3.27^{*} 10 \wedge(-4)$ & .051 & $\begin{array}{l}-.001 ; \\
1.46^{*} 10 \wedge(-6)\end{array}$ & $1.67^{*} 10 \wedge(-4)$ & 937 \\
\hline Conviction that palliative care should be a central part of GP's work & -.145 & $<.001$ & $-.185 ;-.106$ & .020 & 949 \\
\hline Self-assessed palliative competence & -.182 & $<.001$ & $-.230 ;-.135$ & .024 & 939 \\
\hline Extent of GP palliative care delivery (index) & -.334 & $<.001$ & $-.395 ;-.272$ & .031 & 954 \\
\hline Perceived involvement in treatment after SPHC initiation & .116 & $<.001$ & $.080 ; .152$ & .018 & 836 \\
\hline Frequency of SPHC referrals denied by $\mathrm{MDK}^{\mathrm{a}}$ & .017 & .617 & $-.049 ; .082$ & .033 & 811 \\
\hline Number of SPHC referrals by other health care professionals & -.007 & .035 & $-.014 ;-.001$ & .003 & 756 \\
\hline $\begin{array}{l}\text { Qualification level (Reference: none + exclusively within work in general } \\
\text { practice) }\end{array}$ & & & & & 921 \\
\hline Additional qualification in palliative care & -.080 & .158 & $-.191 ; .031$ & .057 & \\
\hline BQKPmV & -.337 & .084 & $-.720 ; .045$ & .195 & \\
\hline 40 h-course certificate & -.068 & .154 & $-.161 ; .025$ & .047 & \\
\hline Having worked in a palliative care institution for at least 3 months & .069 & .342 & $-.073 ; .210$ & .072 & \\
\hline Remuneration level (Reference: PPC) & & & & & 956 \\
\hline Settlement via selective contracts & -.087 & .168 & $-.212 ; .037$ & .063 & \\
\hline BQKPmV & -.399 & .008 & $-.693 ;-.105$ & .150 & \\
\hline PPC + additional qualification in palliative care & -.081 & .201 & $-.204 ; .043$ & .063 & \\
\hline Quality of surrounding palliative infrastructure & .121 & .003 & $.042 ; .201$ & .041 & 869 \\
\hline
\end{tabular}


Table 3 GPs' evaluation of SPHC importance (index), univariate analyses (Continued)

\begin{tabular}{lllll}
\hline Variable & $\begin{array}{l}\text { Regression } \\
\text { Coefficient } \beta\end{array}$ & Significance & $\begin{array}{l}\text { 95\% Confidence } \\
\text { Interval }\end{array}$ & Standard Error $\mathrm{n}$ \\
\hline Quality of utilised SPHC & .241 & $<.001$ & $.187 ; .294$ & .027 \\
\hline
\end{tabular}

${ }^{a}$ Medical advisary service of Social Health Insurance (MDK: Medizinischer Dienst der Krankenkassen)

b Particularly qualified and coordinated general palliative care (translation)

treatment of their patients by the SPHC team, they valued SPHC services as being more important.

Inversely associated with GP-valued SPHC importance were: a certain remuneration level linked to specific palliative care qualification requirements, extent of reported GP palliative care delivery, self-assessed competence, and the conviction that palliative care should be a central part of GPs' work. Furthermore, the frequency of SPHC referrals through other providers, perceived workload, duration of work in the outpatient sector and patients per quarter were related to a lower SPHC importance index. Noticeable differences were found between federal states.

Twenty-two explanatory variables (Table 3 ) were included in the final multiple regression. A residual analysis confirmed that the conditions for multiple regression were met. After all variables were simultaneously entered into the model, four variables finally remained statistically significant (explaining $18.3 \%$ of the total variance, $R^{2}$ ) showing a significant correlation with GP perceived SPHC importance (Table 4): the reported extent of GPs' palliative care delivery, the perceived quality of the utilised SPHC services, the conviction that palliative care should be a central part of GPs' work and involvement in the treatment of palliative patients after SPHC initiation.

Additional univariate analysis demonstrated that the SPHC importance index is solidly associated with the reported number of SPHC referrals $(n=808 ; \beta=0.138$; $p<0.001)$ displaying that GPs with low own palliative care activity and high perception of SPHC-importance reported more SPHC referrals, and GPs with high own palliative care activity and low perception of SPHCimportance reported less SPHC referrals.

\section{Discussion}

\section{Main finding}

The primary finding of this study was that GPs' perception of SPHC importance (as well as reported initiation of SPHC) is mainly driven by their own reported extent of palliative care activities: a GP with high perceived palliative activity values SPHC less; a GP with low activity values SPHC more.

To our knowledge, this is the first (quantitative) study revealing this interrelation from which specific conclusions can be drawn.

The single palliative care activity for which GPs most frequently deemed SPHC support beneficial was "technical and invasive treatment measures", such as morphine pumps, subcutaneous infusions and port systems, required to ensure sufficient symptom control. It is known that the wish to relieve patients' suffering [16], the non-availability of equipment [17] and low self-confidence in applying those measures [18] might lead GPs to seek support, especially with regard to therapeutic options $[16,19]$. Beyond that, specialist support in "treatment in the final phase" was attributed high importance. As patients deteriorate, they are often in need of intensified therapies [20] and increased frequency of out-of-hours home visits [21] - requirements that overload GPs. Additionally, GPs value SPHC more during out-of-hours times (holidays, weekends). This is in line with previous findings which have identified GPs' lack of time and inadequate resources as significant barriers [22-24] to continuously providing palliative care in the final phase.

\section{Further findings}

Further factors influencing GPs' perception of SPHC importance: Firstly, the higher GPs' perceived SPHC quality the higher they rated the importance of SPHC. Although

Table 4 GPs' evaluation of SPHC importance (index), multiple regression analysis ${ }^{a}$

\begin{tabular}{|c|c|c|c|c|}
\hline Variable & $\begin{array}{l}\text { Regression } \\
\text { Coefficient } \beta\end{array}$ & $\begin{array}{l}\text { Signifi- } \\
\text { cance }\end{array}$ & $\begin{array}{l}95 \% \text { Confidence } \\
\text { Interval }\end{array}$ & $\begin{array}{l}\text { Standard } \\
\text { Error }\end{array}$ \\
\hline (Constant) & 2.30 & $<.001$ & $1.69 ; 2.92$ & .315 \\
\hline Extent of GP palliative care delivery (index) & -.283 & $<.001$ & $-.384 ;-.182$ & .051 \\
\hline Conviction that palliative care should be a central part of GPs' work & -.062 & .025 & $-.116 ;-.008$ & .027 \\
\hline $\begin{array}{l}\text { Perceived involvement in treatment of palliative patients after SPHC } \\
\text { initiation }\end{array}$ & .088 & $<.001$ & $.042 ; .134$ & .023 \\
\hline Quality of utilised SPHC & .119 & .001 & $.048 ; .190$ & .036 \\
\hline
\end{tabular}

${ }^{a}$ corrected $\mathrm{R}^{2}=.183, n=559$; only independent variables with significance $<0.05$ are shown 
there is no uniform definition of quality of SPHC, recent studies describe factors contributing to GPs' satisfaction with SPHC teams: timely and appropriate advice and accessible help [25-27], well-developed channels of communication, timely provision of technical expertise [8] and competence of health care providers [27].

Secondly, if SPHC had been initiated, the continuing involvement in the treatment of their patients appears to be relevant to GPs, resulting in a higher appreciation of SPHC. GPs' wish to stay involved in their patients' treatment even if SPHC is involved has been repeatedly emphasised [28]. More critical GP voices regard SPHC as constantly replacing their own role by reducing the active part of GPs in palliative care delivery to bureaucratic functions (i.e. medication prescriptions) [29]. A similar sentiment is displayed by the finding that SPHC referrals by other health care providers (e.g. hospitals) lead to a lack of consideration of the GP's role [30], impeding their perception of SPHC importance.

\section{Interpretation}

The context of current primary care in Germany reveals a highly pressurised work environment [31] with a high workload, which is even more pronounced in rural areas. Hence, the engagement of GPs in palliative care might be impeded due to a lack of resources [24, 32] and limited capacities (experience, competence, knowledge) [33]. Moreover, intergenerational changes in the basic attitude towards the GP profession may lead to decreasing readiness to provide $24 \mathrm{~h}$-care particularly in younger GPs. This is supported by the finding that the extent of GPs' palliative care activities rises with age [34].

Nonetheless, a surrounding palliative care infrastructure besides from SPHC (nursing care services, inpatient palliative care, hospices) GPs perceive as insufficient, keeps them from taking over own responsibility for end-of-life care and drives them to involve SPHC [34] (data analysed, not published yet). As the palliative infrastructure strongly varies between regions [35], GPs' palliative care activities also vary between regions as then does the involvement of SPHC.

As the study design did not capture information on the patient, it remains uncertain how GPs identified a patient's medical need for SPHC. But as it is known that GPs' palliative care activities increase with experience [16], competence [36] and training [37]), we principally assume that GPs' ability to assess the medical need of SPHC improves with the extent of their engagement in palliative care. Against this background, we interpret our results that GPs who are not greatly engaged in palliative care activities involve SPHC as a substitution for PPC tasks they cannot or are not willing to provide themselves due to a lack of resources. Thus, SPHC is partially doing tasks that could be done within PPC if GPs had the necessary resources (time, confidence, professional and financial support). The interpretation is in line with a previous qualitative study by Schneider et al. [29] who already pointed out the link between lacking or insufficient PPC resources and inappropriate SPHC-involvement.

\section{Implications for palliative care politics}

Firstly, instead of reinforcing GPs' withdrawal from palliative care delivery by shifting traditional tasks from GPs to specialists [30], strengthening PPC could be promising. Here, our survey confirms starting points that have been found in qualitative study designs already: Primary care professionals have the potential, ability and motivation to provide palliative care for most patients $[1,38]$ given adequate training, resources, remuneration, a supportive and cooperative surrounding palliative care infrastructure [34] and specialist advice when needed $[24,38,39]$. The latter is particularly important for training GPs in identifying complex cases [40] and for guaranteeing highly qualitative primary palliative care provision during out-of-hours [40, 41].

Nevertheless, there are limits to an enforcement of PPC, due to the high workload GPs in Germany face, which is particularly pronounced in rural areas. That is why, secondly, it should be acknowledged that partially SPHC fills gaps in PPC. This appears to be particularly relevant for $24 \mathrm{~h}$-availability, support in technical care and in the final phase - activities that do not necessarily require special qualifications. And, as there is large regional variation in the capacity of PPC and the general palliative care infrastructure, SPHC has to be regarded as an additional palliative care resource and has to adapt flexible to regional PPC structures.

However, to fill gaps in PPC and to support PPC efficiently, SPHC has to be adjusted with appropriate remuneration structures and adequate - which means not too high - minimum standards for qualification requirements for SPHC-teams as well as requirements regarding a minimum number of professions involved in SPHC. In addition, new forms of cooperation between PPC and SPHC can arise, should be tested and fostered. But always, outcomes of PPC and SPHC (like patient/ relatives' satisfaction as well as costs of care) have to be taken into account when setting the framework.

Not to forget, thirdly, to reduce patients' and relatives' need for palliative support via improving self-help which will take burden from PPC as well as SPHC.

These are all future tasks of palliative (home) care politics our results are pointing at.

\section{Strength and limitations}

This is the first comprehensive, nationwide survey among German GPs addressing the interface of general and specialised palliative homecare from their perspective. 
Even though the response rate of $19.4 \%$ was not too low a response rate compared to our expectations, it naturally limits the representativeness of our results.

Anticipating that responding GPs might be more enthusiastic towards participation in palliative care (apparent in the overrepresentation of GPs with an additional qualification in palliative care), we considered formal experience/qualification level (Additional file 1) as an independent variable in our analysis to avoid a significant distortion in the results attained. Furthermore, we had excluded SPHC-GPs beforehand $(n=118)$ as we supposed that there would be selection bias due to a conflict of interest, especially in terms of remuneration. Only in the descriptive results does the overrepresentation of GPs with higher palliative care experience/ qualification remain.

There may be limitations in terms of the transferability of results to other high-income countries due to health system differences and differences in palliative care delivery. But the general observation of GP' (reported) palliative care activities being inversely associated with GPvalued SPHC importance, the interpretation of this interrelation and the conclusion for actions drawn from this, might, at least partly, also hold for countries other than Germany.

\section{Conclusions}

GPs with low reported activity in palliative care are more likely to initialise SPHC for palliative care activities they do not deliver themselves for various reasons, which might mean that the involvement of SPHC is substitutive instead of complementary to primary palliative care. This finding and its interpretation should be given more attention in the future policy framework for (specialised) palliative homecare in Germany.

\section{Supplementary information}

Supplementary information accompanies this paper at https://doi.org/10. 1186/s12904-020-00603-3.

Additional file 1. The development of the questionnaire.

Additional file 2. Questionnaire: English version.

Additional file 3. GP perceived valuing of SPHC activities.

\section{Abbreviations}

PPC: Primary palliative care, which means generalist palliative homecare (German abbreviation: AAPV); BQKPmV: Particularly qualified and coordinated general palliative care (translation); G-BA: Federal Joint Committee, the highest decision-making body of the joint self-government of physicians, dentists, hospitals and health insurance funds in Germany; KV: (regional) Association of Statutory Health Insurance Physicians; SPHC: Specialised palliative homecare (German abbreviation: SAPV); SGB: Social Code Book

\section{Acknowledgements}

We would like to thank all GPs for their active participation in either their commitment to the generation process, piloting or responding to our survey. We thank Jochen Gensichen. Without his persistence there had not been a GP focused study as one of the five SAVOIR subprojects. We are particularly grateful to Nadine Scholten, Anna Volkert and Sophie Peters for the open and informed exchange during the whole project.

\section{Authors' contributions}

KS and AF drafted the paper. KS developed the questionnaire, conducted the survey and analysed the data. AF planned, headed and supervised the whole study. AF, MK1, HCV and BD contributed to developing the questionnaire. MK1 contributed to public relations to increase GPs' participation. MK2 managed the questionnaire response and digitised the data. TL was the responsible statistician. AF, KS, MK1 and TL interpreted the data. FN, UW, WM, WS, JB, SVS and HCV contributed valuable comments on result interpretation. WS, MJ, MH, SVS, FN, HCV, WM and UW participated in the planning of the study. WM applied for funding. All authors read and approved the final manuscript.

\section{Funding}

SAVOIR is funded by the German Innovations Fund of the Federal Joint Committee in Germany (G-BA) (grant number: 01VSF16005). The funder did not influence the design of the study, the writing of the manuscript and will not influence the collection, analysis and interpretation of data.

\section{Availability of data and materials}

Additional file 2 contains the questionnaire. The datasets used and/or analysed during the current study are available from the corresponding author on reasonable request.

\section{Ethics approval and consent to participate}

Written approval from the local ethics committee was obtained from Jena University Hospital (No. 5316-10/17). Informed consent was implied if the completed questionnaire was sent back.

Consent for publication

Not applicable.

\section{Competing interests}

The authors declare that they have no competing interests.

\section{Author details}

${ }^{1}$ Institute of General Practice and Family Medicine, Jena University Hospital, Jena, Germany. ${ }^{2}$ German Working Group for SAPV, Berlin, Germany. ${ }^{3}$ Clinic for Palliative Medicine, University Medical Center Göttingen, Göttingen, Germany. ${ }^{4}$ Center for Clinical Studies, Jena University Hospital, Jena, Germany. ${ }^{5}$ Department of Palliative Care, Jena University Hospital, Jena, Germany. ${ }^{6}$ Center for Interdisciplinary Health Research, University of Augsburg, Augsburg, Germany. ${ }^{7}$ Institute of General Practice and Family Medicine, Faculty of Medicine, Ruhr University Bochum, Bochum, Germany.

Received: 4 November 2019 Accepted: 24 June 2020

Published online: 03 August 2020

\section{References}

1. Schneider N, Mitchell GK, Murray SA. Palliative care in urgent need of recognition and development in general practice: the example of Germany. BMC Fam Pract. 2010;11:66. https://doi.org/10.1186/1471-2296-11-66.

2. Radbruch L, Andersohn F, Walker J. Palliativversorgung: Überversorgung kurativ - Unterversorgung palliativ? 2015. https:/faktencheckgesundheit.de/ de/faktenchecks/faktencheck-palliativversorgung/ergebnis-ueberblick/. Accessed 9 May 2019

3. Gemeinsamer Bundesausschuss. Richtlinie zur Verordnung von spezialisierter ambulanter Palliativversorgung. https://www.g-ba.de/richtlinien/64/.

4. Gemeinsamer Bundesausschuss. Bericht an das Bundesministerium für Gesundheit über die Umsetzung der SAPV-Richtlinie für das Jahr 2016. 2017. https://www.g-ba.de/informationen/richtlinien/64/. Accessed 6 Mar 2019.

5. Grabenhorst U. Specialized ambulatory palliative care: (SAPV) 5-year results of a multi-professional care model by HomeCare linker Niederrhein $\mathrm{gGmbH}$ $(\mathrm{HC})$ in the Lower Rhine region. Ann Oncol. 2017. https://doi.org/10.1093/ annonc/mdx382.010. 
6. Schneider N, Engeser P, Behmann M, Kühne F, Wiese B. Spezialisierte ambulante Palliativversorgung. Die Erwartungen von Hausärzten. Schmerz 2011;25(166):168-73. https://doi.org/10.1007/s00482-011-1037-0.

7. Peng J-K, Chiu T-Y, Hu W-Y, Lin C-C, Chen C-Y, Hung S-H. What influences the willingness of community physicians to provide palliative care for patients with terminal cancer? Evidence from a nationwide survey. Jpn J Clin Oncol. 2013;43:278-85. https://doi.org/10.1093/jjco/hys222.

8. Rhee JJ, Teo PCK, Mitchell GK, Senior HE, Tan AJH, Clayton JM. General practitioners (GPS) and end-of-life care: a qualitative study of Australian GPS and specialist palliative care clinicians. BMJ Support Palliat Care. 2018. https://doi.org/10.1136/bmjspcare-2018-001531.

9. Gardiner C, Gott M, Ingleton C. Factors supporting good partnership working between generalist and specialist palliative care services: a systematic review. Br J Gen Pract. 2012;62:e353-62. https://doi.org/10.3399/bjgp12X641474.

10. Carduff E, Johnston S, Winstanley C, Morrish J, Murray SA, Spiller J, Finucane A. What does 'complex' mean in palliative care? Triangulating qualitative findings from 3 settings. BMC Palliat Care. 2018;17:12-8. https://doi.org/10. 1186/s12904-017-0259-z.

11. Burt J, Shipman C, White P, Addington-Hall J. Roles, service knowledge and priorities in the provision of palliative care: a postal survey of London GPs. Palliat Med. 2006;20:487-92. https://doi.org/10.1191/0269216306pm1159oa.

12. Freytag A, Krause M, Bauer A, Ditscheid B, Jansky M, Krauss S, et al. Study protocol for a multi-methods study: SAVOIR - evaluation of specialized outpatient palliative care (SAPV) in Germany: outcomes, interactions, regional differences. BMC Palliat Care. 2019;18:12. https://doi.org/10.1186/ s12904-019-0398-5.

13. Kelley K, Clark B, Brown V, Sitzia J. Good practice in the conduct and reporting of survey research. Int J Qual Health Care. 2003;15:261-6. https:// doi.org/10.1093/intqhc/mzg031

14. von Elm E, Altman DG, Egger M, Pocock SJ, Gøtzsche PC, Vandenbroucke JP. The Strengthening the Reporting of Observational Studies in Epidemiology (STROBE) Statement: guidelines for reporting observational studies. Int J Surg. 2014;12:1495-9. https://doi.org/10.1016/j.ijsu.2014.07.013.

15. Bundesärztekammer. Ärztestatistik zum 31. Dezember 2018. https://www. bundesaerztekammer.de/ueber-uns/aerztestatistik/. Accessed 13 June 2019.

16. Mitchell GK, Senior HE, Johnson CE, Fallon-Ferguson J, Williams B, Monterosso $L$, et al. Systematic review of general practice end-of-life symptom control. BMJ Support Palliat Care. 2018;8:411-20. https://doi.org/ 10.1136/bmjspcare-2017-001374.

17. Ramanayake RPJC, Dilanka GVA, Premasiri LWSS. Palliative care; role of family physicians. J Family Med Prim Care. 2016;5:234-7. https://doi.org/10.4103/ 2249-4863.192356.

18. Winthereik A, Neergaard M, Vedsted $P$, Jensen A. Danish general practitioners' self-reported competences in end-of-life care. Scand J Prim Health Care. 2016;34:420-7. https://doi.org/10.1080/02813432.2016.1249059.

19. Beccaro M, Lora Aprile P, Scaccabarozzi G, Cancian M, Costantini M. Survey of Italian general practitioners: knowledge, opinions, and activities of palliative care. J Pain Symptom Manage. 2013;46:335-44. https://doi.org/10. 1016/j.jpainsymman.2012.08.020.

20. Geist MJP, Bardenheuer HJ, Weigand MA, Frankenhauser S, Kessler J. Möglichkeiten der spezialisierten ambulanten Palliativversorgung. Urologe A. 2018;57:563-7. https://doi.org/10.1007/s00120-018-0571-0.

21. Pierau A. Hausärztliche Versorgung am Lebensende (HAVEL): Eine retrospektive Befragung von Hausärzten. Göttingen: Georg-AugustUniversität; 2013.

22. Plat FM, Peters YAS, Giesen P, Smits M. Availability of Dutch General practitioners for after-hours palliative care. J Palliat Care. 2018;33:182-6. https://doi.org/10.1177/0825859718766947.

23. Giezendanner S, Jung C, Banderet H-R, Otte IC, Gudat H, Haller DM, et al, General practitioners' attitudes towards essential competencies in end-oflife care: a cross-sectional survey. PLoS One. 2017;12:e0170168. https://doi. org/10.1371/journal.pone.0170168.

24. Malik S, Goldman R, Kevork N, Wentlandt K, Husain A, Merrow N, et al. Engagement of primary care physicians in home palliative care. J Palliat Care. 2017;32:3-10. https://doi.org/10.1177/0825859717706791.

25. Shipman C, Addington-Hall J, Barclay S, Briggs J, Cox I, Daniels L, Millar D. How and why do GPs use specialist palliative care services? Palliat Med. 2002;16:241-6. https://doi.org/10.1191/0269216302pm534oa.

26. Hanratty B. GP views on developments in palliative care services. Palliat Med. 2000:14:223-4. https://doi.org/10.1191/026921600666744722.
27. Koné I, Klein G, Siebenhofer A, Dahlhaus A, Güthlin C. GPs' assessment of cooperation with other health care providers involved in cancer care-a crosssectional study. Eur J Cancer Care (Engl). 2018. https://doi.org/10.1111/ecc.12751.

28. Dahlhaus A, Vanneman N, Guethlin C, Behrend J, Siebenhofer A. German general practitioners' views on their involvement and role in cancer care: a qualitative study. Fam Pract. 2014;31:209-14. https://doi.org/10.1093/fampra/cmt088.

29. Schneider W, Eichner E, Thoms U, Kopitzsch F, Stadelbacher S. Struktur- und Prozesseffekte der SAPV in Bayern - Evaluation / Qualitätssicherung und (Aus-)Wirkungen der SAPV auf die AAPV (unter besonderer Berücksichtigung des ländlichen Raums): Ergebnisbericht. Augsburg; 2014.

30. Schwabe S, Ates G, Ewert B, Hasselaar J, Hesse M, Linge-Dahl L, et al. "He is not that important anymore" : General practitioners in a specialized palliative home care setting from a patient's point of view. Bundesgesundheitsbl. 2017;60:5561. https://doi.org/10.1007/s00103-016-2478-5.

31. Mitchell S, Loew J, Millington-Sanders C, Dale J. Providing end-of-life care in general practice: findings of a national GP questionnaire survey. $\mathrm{Br} J$ Gen Pract. 2016;66:e647-53. https://doi.org/10.3399/bjgp16X686113.

32. Rhee JJ-O, Zwar N, Vagholkar S, Dennis S, Broadbent AM, Mitchell G. Attitudes and barriers to involvement in palliative care by Australian urban general practitioners. J Palliat Med. 2008;11:980-5. https://doi.org/10.1089/ jpm.2007.0251.

33. Weiskopf G, Meyer M, Renaud D. Im Augenblick des Lebens: AAPV oder SAPV?: Unsicherheiten in der Entscheidungsfindung zwischen AAPV und SAPV - Eine qualitative Studie. Palliativmedizin. 2018;19:197-204. https://doi. org/10.1055/a-0608-7226.

34. Freytag A, Krause M, Lehmann T, Völker M-L, Kaufmann M, Ditscheid B, et al. Einflussfaktoren für den Umfang hausärztlicher Palliativversorgung Ergebnisse einer bundesweiten Befragungsstudie. 53. Erlangen: Kongress für Allgemeinmedizin und Familienmedizin (DEGAM); 2019.

35. Deutsche Gesellschaft für Palliativmedizin. Wegweiser Hospiz- und Palliativversorgung Deutschland. https://www.dgpalliativmedizin.de/images/ stories/pdf/161231_Wegweiser\%C3\%BCbersicht_Homepage_Erwachsene. pdf. Accessed 28 Oct 2019.

36. Farber NJ, Urban SY, Collier VU, Metzger M, Weiner J, Boyer EG. Frequency and perceived competence in providing palliative care to terminally ill patients: a survey of primary care physicians. J Pain Symptom Manage. 2004:28:364-72. https://doi.org/10.1016/j.jpainsymman.2004.01.013.

37. Thoonsen B, Gerritzen SHM, Vissers KCP, Verhagen S, van Weel C, Groot M, Engels $Y$. Training general practitioners contributes to the identification of palliative patients and to multidimensional care provision: secondary outcomes of an RCT. BMJ Support Palliat Care. 2019;9:e18. https://doi.org/10. 1136/bmjspcare-2015-001031.

38. Murray SA, Kok JY. Internationally, it is time to bridge the gap between primary and secondary healthcare services for the dying. Ann Acad Med Singapore. 2008;37:142-4.

39. Mitchell S, Tan A, Moine S, Dale J, Murray SA. Primary palliative care needs urgent attention. BMJ. 2019;365:11827. https://doi.org/10.1136/bmj.l1827.

40. Magee C, Koffman J. Out-of-hours palliative care: what are the educational needs and preferences of general practitioners? BMJ Support Palliat Care. 2016:6:362-8. https://doi.org/10.1136/bmispcare-2014-000764.

41. Williams H, Donaldson L, Noble S, Hibbert P, Watson R, Kenkre J, et al. Quality improvement priorities for safer out-of-hours palliative care: Lessons from a mixed-methods analysis of a national incident-reporting database. Palliat Med. 2019;33:346-56. https://doi.org/10.1177/0269216318817692.

\section{Publisher's Note}

Springer Nature remains neutral with regard to jurisdictional claims in published maps and institutional affiliations. 